\title{
Effects of cobalt-chromium everolimus eluting stents or bare metal stent on fatal and non-fatal cardiovascular events: patient level meta-analysis
}

\author{
(c) (1) (8) OPEN ACCESS
}

\begin{abstract}
Marco Valgimigli associate professor of medicine ${ }^{1}$, Manel Sabaté associate professor of medicine ${ }^{2}$, Christoph Kaiser professor of medicine ${ }^{3}$, Salvatore Brugaletta assistant professor of medicine ${ }^{2}$, Jose Maria de la Torre Hernandez associate professor of medicine ${ }^{4}$, Soeren Galatius interventional cardiologist ${ }^{5}$, Angel Cequier associate professor of medicine ${ }^{6}$, Franz Eberli professor of medicine ${ }^{7}$, Adam de Belder interventional cardiologist ${ }^{8}$, Patrick W Serruys professor of medicine ${ }^{1}$, Giuseppe Ferrante interventional cardiologist ${ }^{9}$
\end{abstract}

${ }^{1}$ Thoraxcenter, Erasmus Medical Center, 3015 CE Rotterdam, Netherlands; ${ }^{2}$ University Hospital Clinic, IDIBAPS, Cardiology Department, 08036 Barcelona, Spain; ${ }^{3}$ University Hospital 4003 Basel, Switzerland; ${ }^{4}$ Hospital Marqués de Valdecilla, 39008 Santander, Spain; ${ }^{5}$ Gentofte Hospital, 2900 Hellerup, Denmark; ${ }^{6}$ University Hospital of Bellvitge, 08907 Barcelona, Spain; ${ }^{7}$ Stadtspital Triemli, 8063 Zürich, Switzerland; ${ }^{8}$ Brighton and Sussex University Hospitals NHS Trust, Brighton BN1 6AG, UK; ${ }^{9}$ Interventional Cardiology, Humanitas Clinical and Research Institute IRCCS, 20089 Rozzano, Milan, Italy

\begin{abstract}
Objectives To examine the safety and effectiveness of cobalt-chromium everolimus eluting stents compared with bare metal stents.

Design Individual patient data meta-analysis of randomised controlled trials. Cox proportional regression models stratified by trial, containing random effects, were used to assess the impact of stent type on outcomes. Hazard ratios with $95 \%$ confidence interval for outcomes were reported.

Data sources and study selection Medline, Embase, the Cochrane Central Register of Controlled Trials. Randomised controlled trials that compared cobalt-chromium everolimus eluting stents with bare metal stents were selected. The principal investigators whose trials met the inclusion criteria provided data for individual patients.

Primary outcomes The primary outcome was cardiac mortality. Secondary endpoints were myocardial infarction, definite stent thrombosis, definite or probable stent thrombosis, target vessel revascularisation, and all cause death.

Results The search yielded five randomised controlled trials, comprising 4896 participants. Compared with patients receiving bare metal stents, participants receiving cobalt-chromium everolimus eluting stents had a significant reduction of cardiac mortality (hazard ratio $0.67,95 \%$ confidence interval 0.49 to $0.91 ; P=0.01)$, myocardial infarction $(0.71$,
\end{abstract}

0.55 to $0.92 ; P=0.01)$, definite stent thrombosis $(0.41,0.22$ to 0.76 ; $\mathrm{P}=0.005)$, definite or probable stent thrombosis $(0.48,0.31$ to 0.73 ; $P<0.001)$, and target vessel revascularisation $(0.29,0.20$ to 0.41 ; $\mathrm{P}<0.001)$ at a median follow-up of 720 days. There was no significant difference in all cause death between groups $(0.83,0.65$ to $1.06 ; \mathrm{P}=0.14)$. Findings remained unchanged at multivariable regression after adjustment for the acuity of clinical syndrome (for instance, acute coronary syndrome $v$ stable coronary artery disease), diabetes mellitus, female sex, use of glycoprotein Ilb/IIla inhibitors, and up to one year $v$ longer duration treatment with dual antiplatelets.

Conclusions This meta-analysis offers evidence that compared with bare metal stents the use of cobalt-chromium everolimus eluting stents improves global cardiovascular outcomes including cardiac survival, myocardial infarction, and overall stent thrombosis.

\section{Introduction}

Randomised controlled trials, ${ }^{12}$ a meta-analysis, ${ }^{3}$ and an observational study ${ }^{4}$ have consistently shown reduced rates of target vessel revascularisation because of angiographic restenosis and ischaemia after treatment with drug eluting stents compared with bare metal stents. As a result, most percutaneous coronary interventions are done with drug eluting stents rather than bare metal stents. The higher rates of late stent thrombosis and the 
concern about higher risks of late stent thrombosis after early discontinuation of dual antiplatelet therapy with first generation drug eluting stents, however, have raised safety concerns. ${ }^{56}$ New drug eluting stents have been developed with novel materials, designs, and delivery systems, with biocompatible polymers and new antiproliferative agents. The box gives details of the types of stents. Most of these second generation stents, however, were approved after non-inferiority trials in which they were compared with first generation drug eluting stents. ${ }^{7-10}$ Few studies have directly compared second generation drug eluting stents with bare metal stents, and their comparative safety profile remains unclear.

Recent studies have reported a possible lower risk of stent thrombosis after implantation with cobalt-chromium everolimus eluting stents compared with bare metal stents. ${ }^{11-13}$ The implications of this finding on clinical outcomes are currently unknown.

We undertook a collaborative analysis of data from randomised trials of patients who underwent random allocation to either cobalt-chromium everolimus eluting stents or bare metal stents to assess the comparative safety and efficacy of these two devices on fatal and non-fatal cardiovascular outcomes.

\section{Methods}

\section{Search strategy and study selection}

Two investigators (MV and GF) independently searched Medline, Embase, and the Cochrane Central Register of Controlled Trials (from database inception to December 2013) using the terms everolimus eluting stent and bare metal stent. A sensitive filter for randomised controlled trials was used. There were no restrictions by language, publication date, or publication status. We hand searched conference proceedings (from 2006 to 2013) of the American Heart Association, the American College of Cardiology, the Transcatheter Cardiovascular Therapeutics, and the European Society of Cardiology. All suitable non-published completed registered studies were considered for inclusion. We checked reference lists of identified articles, recent editorials, and related reviews and contacted experts for further eligible trials.

\section{Trial eligibility and quality assessment}

Two investigators (MV and GF) independently assessed trial eligibility. Randomised trials comparing two or more different drug eluting stents or drug eluting stents with bare metal stents were eligible for inclusion. Inclusion criteria comprised randomised treatment allocation, comparison of cobalt-chromium everolimus eluting stent versus bare metal stent, and length of follow-up of at least a year. Exclusion criteria were equivocal or non-random treatment allocation, lack of outcome data up to one year, and duplicate reports. The two reviewers resolved disagreements by consensus. All included trials were reviewed and approved by ethics committees, and all participants had given written informed consent. Two investigators (MV and GF) systematically assessed the presence of sources of bias by following the approach recommended by the Cochrane Collaboration that identifies selection, performance, attrition, detection, reporting bias, and other sources of bias for each study, and classifies each of these as low, unclear, or high by analysing the following domains: random sequence generation, allocation concealment, blinding of participants and of outcome assessment, incomplete outcome data, selective outcome reporting, and "other issues."14 Disagreements were resolved through consensus. A risk of bias summary for each item for each included study was reported.
The meta-analysis was performed in agreement with the PRISMA statement. ${ }^{15}$

\section{Data extraction}

We invited the principal investigators whose trials met the inclusion criteria to participate in this collaborative analysis, and they provided the following data for individual patients: a set of core clinical variables consisting of demographics (age, sex, body mass index (BMI)), cardiac risk factors (diabetes, smoking, hypertension, and hypercholesterolaemia), clinical manifestations (stable coronary artery disease, cardiac markers negative unstable coronary artery disease, cardiac markers positive unstable coronary artery disease without persistent ST segment elevation myocardial infarction and persistent ST segment myocardial infarction), angiographic factors (number and type of diseased vessels, number of treated lesions, number of implanted stents, overlapping stents implantation, total stent length and average stent diameter), use of antithrombotic drugs (actual duration of clopidogrel after treatment and use of glycoprotein IIb/IIIa inhibitors during the procedure), randomised treatment assignment, and outcomes in follow-up (death, cardiac death, myocardial infarction, stent thrombosis, repeat revascularisation, and last follow-up contact).

Two investigators (MV, GF) extracted data independently on trial design, baseline characteristics, outcomes, and safety events. After resolution of data queries, we recoded data from each trial in a single dataset and checked data summaries from individual trials against the associated publications for accuracy.

\section{Endpoints}

The primary outcome was cardiac mortality at the longest available follow-up. We selected cardiac mortality and not all cause mortality as primary outcome measure to minimise the confounding effect of non-cardiac events on stent performance in the context of a relatively old and unselected population of patients followed-up through two years. Importantly, cardiac mortality was homogenously classified across the five included studies according to the ARC (Academic Research Consortium) criteria. $^{16}$

Secondary outcomes were all cause death, myocardial infarction (fatal and non-fatal), stent thrombosis (definite and definite or probable), target vessel revascularisation, a composite of cardiac death and myocardial infarction, and a composite of all cause death and myocardial infarction. The definition of stent thrombosis was in alignment with the ARC criteria in four out of five studies, ${ }^{11-13}{ }^{17-19}$ whereas in the SPIRIT I trial ${ }^{20}$ stent thrombosis was defined as a total coronary artery occlusion by angiography at the stent site with abrupt onset of symptoms, raised biochemical markers, and changes on electrocardiography consistent with myocardial infarction. The definition of myocardial infarction, which is summarised in table $\mathrm{A}$ in appendix 1, differed among included trials largely because of different criteria used to adjudicate peri-procedural events. ${ }^{11-13}{ }^{17-20}$ For all five studies, fatal and non-fatal cardiovascular endpoints were confirmed on the basis of documentation collected at each hospital and were centrally adjudicated by clinical events committees, whose members were unaware of patients' assignments to treatment group.

\section{Statistical analysis}

We carried out an individual patient level data meta-analysis using a "one stage" approach. Briefly, all data from individual participants were combined in a single meta-analysis based on a simple Cox proportional regression model stratified by trial, 


\section{Bare metal stents}

A bare metal stent is vascular stent without a coating (as used in drug eluting stents). It is a mesh-like tube of thin wire. The first stents licensed for use in cardiac arteries were bare metal-often 316 L stainless steel. More recent ("second generation") stents use cobalt chromium alloy. The major limitation of this coronary device is the so called risk for in stent restenosis, caused by proliferation of cells in the media layer of the vessel wall leading to the growth of new tissue within the stent struts, called intimal hyperplasia, finally narrowing the vessel lumen in a sizable proportion of patients. The growth of intimal hyperplasia peaks on average a few months after stent implantation and remains thereafter stable. This stent requires the use of dual antiplatelet therapy for 30 days.

\section{First generation drug eluting stents}

They were primarily conceived to reduce in stent neointimal formation and therefore minimise the occurrence of restenosis, the major drawback of percutaneous coronary interventions with bare metal stents. They consist of a metallic vascular stent coated with a permanent polymer, which slowly releases a drug, such as sirolimus or paclitaxel, to block cell proliferation and thus limit intimal hyperplasia. The permanent presence of these polymers has been associated with inflammatory responses and local toxicity in preclinical analysis. The optimal duration of dual antiplatelet therapy after first generation drug eluting stents has never been conclusively determined, but it is likely to be more than a year as this device has been associated with a fourfold to fivefold risk for very late (that is, after one year) stent thrombosis compared with bare metal stents. On the other hand, rates of acute, subacute, and late stent thrombosis have been shown to be equal or even lower than with bare metal stents.

\section{Second generation drug eluting stents}

They have been developed with thinner, more biocompatible, permanent, or bioabsorbable polymers, and new antiproliferative agents. Whether technology based on erodible polymers - such as poly-l-lactic acid and poly-D, L-lactide, which control drug release after implantation and vanish thereafter-is truly superior to technology engineered with biocompatible, thin, and durable material such as the fluorinated polymer present in the cobalt-chromium everolimus eluting stent is still matter of debate. Second generation drug eluting stents have largely been compared with first generation devices and some of them have been shown to be associated with a much lower risk of stent thrombosis, both early and late. As with first generation drug eluting stents, the optimal duration of dual antiplatelet therapy after second generation drug eluting stents has never been conclusively determined. No randomised study has so far reported safety issues in patients who discontinued dual antiplatelet therapy after six or even three months after their implantation.

While first generation drug eluting stents have now been withdrawn from the market, clinical decision making regarding second generation drug eluting stents versus bare metal stents currently depends on a complex interplay of several factors, including perceived risk for in stent restenosis - if the perceived risk is low, a bare metal stent might be preferable, contraindications to long term dual antiplatelet therapy, and costs.

containing random effects (frailty models) to assess the impact of stent type-for instance, cobalt-chromium everolimus eluting stent versus bare metal stent on outcome measures. ${ }^{21} \mathrm{We}$ calculated hazard ratios and $95 \%$ confidence interval for the endpoints.

We also assessed the impact of stent type on outcomes by multivariable Cox regression stratified by trial, with random effects, entering into the model the following prespecified clinically relevant covariates: clinical syndrome (that is, acute coronary syndrome $v$ stable syndrome), history of diabetes mellitus, female sex, use of glycoprotein IIb/IIIa inhibitors, and up to one year versus longer duration of dual antiplatelet therapy. For each endpoint, we performed time to first event analysis. When assessing each individual endpoint, we censored patients who died from any cause beyond the time of death - that is, they were not at risk anymore for the endpoint assessed after they died.

We verified the proportional hazard assumptions by applying a test for non-proportional hazards with the Schoenfeld residuals and by visual estimation after plotting graphs of the scaled Schoenfeld residuals against transformed time at follow-up after index procedure and by adding time-by-covariate interactions for each variable of the model, by introducing products between the variables and a linear function of time.

As secondary analyses, we performed competing risk regression models for endpoints other than death, considering all cause mortality as the competing event. We calculated subhazard ratios with $95 \%$ confidence interval (according to the method of Fine and Gray, ${ }^{22}$ accounting for the clustered nature of the data with trial as cluster) and have reported them in a supplemental table. Subhazard ratios refer to the hazard that generates failure events of interest while keeping participants who experience competing events "at risk" so that they can be adequately counted as not having any chance of failing.

In case of violation of the proportional hazard assumptions, we calculated and report time dependent hazard ratios.

For target vessel revascularisation, and the composite of target vessel revascularisation or myocardial infarction, for which stent type effect presented a violation in proportional hazard assumptions in both main and competing risk analyses, we report a plot depicting Schoenfeld-like residuals against time with a lowess smooth fitted through it from simple competing risk regression model.

For outcomes not treated as competing events, we report cumulative hazard curves of events, derived directly from the simple Cox regression model built for hazard ratio calculation. For endpoints assessed in competing risk analyses, we report cumulative incidence curves of events, derived from the corresponding simple regression model.

The numbers of patients needed to treat for an additional beneficial or harmful outcome were calculated according to the formula: $\mathrm{NTT}=1 /\{[\mathrm{Sc} 1(\mathrm{t})]-\mathrm{Sc} 0(\mathrm{t})\}$, where the $\mathrm{Sc} 0(\mathrm{t})$ is the survival probability at two years in the bare metal group and [Sc1(t)] is the survival probability at two years in the cobalt-chromium everolimus eluting stent group. Survival probabilities were derived from simple Cox regression model for mortality endpoints after estimation of baseline survival functions and from simple competing risk regression model for non-mortality endpoints.

We evaluated the presence of heterogeneity among studies with the variance of random effects estimated by multivariable stratified Cox regression models with random effects. Additionally, we performed classic meta-analytic estimates of heterogeneity with the Cochran $\mathrm{Q} \chi^{2}$ test, where a $\mathrm{P}$ value $\leq 0.10$ was considered as significant; with estimation of the variance between studies with $\tau^{2}$ and by using $\mathrm{I}^{2}$ test to evaluate the inconsistency. The $\mathrm{I}^{2}$ statistic is derived from the $\mathrm{Q}$ statistic ([Q-df/Q]*100) and describes the percentage of total variation across studies attributable to heterogeneity: values of $25 \%, 50 \%$, and $75 \%$ correspond to low, moderate, and high heterogeneity. ${ }^{23}$ We could not statistically assess publication bias because we had fewer than 10 studies. All analyses were conducted according to the intention to treat principle. Categorical variables are reported as counts and percentages and were compared by $\chi^{2}$ or Fisher's exact tests as appropriate. Continuous variables are reported as means and SD or median and interquartile ranges 
whenever appropriate and were compared by $t$ tests or Mann Whitney $\mathrm{U}$ test as appropriate.

\section{Subgroup analyses}

We tested for interactions between assigned treatment and baseline characteristics for the primary outcome measure of cardiac death using stratified Cox models with random effects that included treatment assignment, the baseline characteristic of interest, and their interaction. We report coefficient interactions with standard errors and $\mathrm{P}$ values for interaction. The following covariates were tested for interaction: age $\geq 65$, sex, diabetes, use of glycoprotein IIb/IIIa inhibitors, duration of dual antiplatelet therapy up to one year versus longer, overlapping stent, clinical syndrome (acute coronary syndrome/stable angina), treated culprit vessel, left descending artery versus no left descending artery, and multi-vessel disease. For descriptive purposes only, we have provided a plot of treatment effects within each subgroup.

\section{Sensitivity analyses}

In a sensitivity analysis, we assessed the impact of treatment assignment on main outcome measure after censoring all patients with cardiac fatalities temporarily associated (that is, occurring within one week) with the occurrence of definite or probable stent thrombosis.

In another sensitivity analysis we excluded one study (SPIRIT I) with a sample size of fewer than 100 patients and assessed the main outcome measure.

The level of significance for the summary treatment effect estimate was two tailed $\mathrm{P}<0.05$. We used $\mathrm{R}$ version 2.13.2 (the $\mathrm{R}$ foundation for statistical computing), Stata 11.2 statistical software (Statacorp LP, College Station, TX), and Review Manager (RevMan) version 5.1 (2011, Nordic Cochrane Centre, Cochrane Collaboration, Copenhagen) for statistical analyses.

\section{Results}

Of the 346 citations screened, we selected five randomised controlled trials (fig $1 \Downarrow$ ). ${ }^{11-13} 17-20$

The five participating trials provided data on 4896 patients (tables $1-3 \Downarrow \Downarrow \Downarrow$ ). The average age of the study population was 67 , with about $57 \%$ and $33 \%$ patients aged 65 or 75 or older, respectively. The XIMA population had the highest mean age (83), followed by PRODIGY (69), BASKET PROVE (64), SPIRIT I (63), and EXAMINATION (61). Table 1 shows the baseline characteristics of the patients included in the trials. $\downarrow$ Overall, the proportion of women was slightly over $24 \%$ and ranged from almost $40 \%$ in XIMA to $17 \%$ in EXAMINATION. Diabetes mellitus was present in roughly $19 \%$ of overall included patients. As a result of including two all comer percutaneous coronary intervention studies ${ }^{11}{ }^{13}$ and one all comer ST segment myocardial infarction trial, ${ }^{12} 44 \%$ of patients $(n=2129)$ received stenting in the setting of primary percutaneous coronary intervention (table $2 \Downarrow$ ) and more than $87 \%(\mathrm{n}=4279)$ of patients underwent coronary treatment for an unstable presentation, including $22 \%(n=1083)$ of patients with non-ST segment myocardial infarction. The recommended duration of treatment with clopidogrel after stenting differed across studies, from one year for BASKET PROVE, at least one year for EXAMINATION, at least three months in SPIRIT I, and up to 6 or 24 months, according to the randomisation scheme, in PRODIGY (table $3 \Downarrow$. In the XIMA trial, the recommended duration of clopidogrel was three months after bare metal stents and 12 months after cobalt-chromium everolimus eluting stents.

Notably, the comparator bare metal stent arm was homogenised with the use of cobalt-chromium Vision stent in BASKET PROVE, EXAMINATION, SPIRIT I, and XIMA ${ }^{17}$ whereas the choice of bare metal stent type was left at the discretion of the treating physician in PRODIGY.

Median duration of follow-up was 720 days (interquartile range 719-720) in both groups. Complete two year follow-up data were available for four studies, ${ }^{11}{ }^{18-20}$ including 3933 (80.3\%) patients. Thirty nine $(0.8 \%)$ patients (19 in the bare metal and 17 in the cobalt-chromium everolimus eluting stent group) were lost to follow-up.

\section{Bias assessment}

Figure 2 shows the systematic bias analysis $\Downarrow$. There was a low risk of bias for most items for each study, except for the presence of performance bias because of the lack of the double blind design in each study. Further the potential for selection bias in the SPIRIT I study was acknowledged.

\section{Mortality endpoints}

At two years, the risk of cardiac death was significantly reduced in the cobalt-chromium everolimus eluting stent group at $2.7 \%$ compared with $4.0 \%$ in the bare metal stent arm (hazard ratio $0.67,95 \%$ confidence interval 0.49 to $0.91 ; \mathrm{P}=0.01$; fig $3 \Downarrow$, table $4 \Downarrow$. With multivariable regression, cardiac mortality remained significantly lower in the cobalt-chromium everolimus eluting stent group $(0.69,0.50$ to $0.94 ; \mathrm{P}=0.02$; table 4$)$.

Overall mortality was not significantly reduced in the cobalt-chromium everolimus eluting stent group (4.9\% v 5.9\%; unadjusted hazard ratio $0.83,95 \%$ confidence interval 0.65 to 1.06; $\mathrm{P}=0.14$; adjusted hazard ratio $0.84,0.66$ to $1.07 ; \mathrm{P}=0.16$ ) (table $4 \Downarrow$, fig $\mathrm{A}$ in appendix 2). There was evidence for small non-significant heterogeneity for cardiac mortality (table A in appendix 1).

\section{Other fatal and/or non-fatal cardiovascular endpoints}

At two years, the risk of myocardial infarction was significantly lower in the cobalt-chromium everolimus eluting stent group (4.0\% $v 5.6 \%$ in the bare metal stent group; unadjusted hazard ratio $0.71,95 \%$ confidence interval 0.55 to $0.92 ; \mathrm{P}=0.01$; adjusted hazard ratio $0.71,0.55$ to $0.93 ; \mathrm{P}=0.01$ (table $4 \Downarrow$, fig $4 \Downarrow)$.

The risk of fatal myocardial infarction was significantly lower in the cobalt-chromium everolimus eluting stent group (unadjusted hazard ratio $0.11,95 \%$ confidence interval 0.03 to $0.48, \mathrm{P}=0.003$; adjusted hazard ratio $0.11,0.03$ to $0.49, \mathrm{P}=0.004$; table 4 , fig $5 \Downarrow$ ). No significant difference in the risk of non-fatal myocardial infarction between groups was found (table 4, fig B in appendix 2). $\downarrow$

Similarly, at two years the risk of definite stent thrombosis $(0.6 \%$ v $1.4 \%$; adjusted hazard ratio $0.41,95 \%$ confidence interval 0.22 to $0.76 ; \mathrm{P}=0.005$; table $4 \Downarrow$, fig $6 \Downarrow)$, definite or probable stent thrombosis $(1.3 \% v 2.6 \% ; 0.48,0.31$ to 0.73 ; $\mathrm{P}=0.001$; table 4 , fig $7 \Downarrow)$, and the need for re-intervention in the previously treated vessel ( $4.3 \% v 10.2 \%$; adjusted hazard ratio $0.29,0.20$ to $0.41 ; \mathrm{P}<0.001$; table 4 , fig $8 \Downarrow$ ) were all consistently at least halved in the cobalt-chromium everolimus eluting stent group.

Rates of the composite of target vessel revascularisation or myocardial infarction, cardiac death or myocardial infarction, 
death, or myocardial infarction were significantly lower in the cobalt-chromium everolimus eluting stent group (table $4 \Downarrow$, figs C-E in appendix 2).

Subhazard ratios calculated in competing risk analyses were consistent with results of the main analysis for each endpoint (table B in appendix 1).

For target vessel revascularization, and the composite of target vessel revascularisation or myocardial infarction, we report a plot depicting Schoenfeld-like residuals against time because of the presence of time dependent hazard ratios (fig $\mathrm{F}$ in appendix 2). Table $\mathrm{C}$ in appendix 1 shows the numbers needed to treat for each endpoint.

Heterogeneity was null or minimal for the endpoints assessed. We found a small non-significant heterogeneity for target vessel revascularisation only (table $\mathrm{A}$ in appendix 1).

\section{Subgroups and sensitivity analyses}

As shown in figure $9 \Downarrow$, the benefit of treatment with cobalt-chromium everolimus eluting stents was consistent across all analysed subgroups, including sex, age $\geq 65$, presence of diabetes, extension of coronary artery disease, need for overlapping stents during the procedure, use of glycoprotein IIb/IIIa inhibitors, treatment of left anterior descending artery, and duration of dual antiplatelet therapy up to one year or beyond.

We found an interaction for the type of coronary artery disease at the time of intervention, indicating that patients presenting with a stable disease phenotype might have a greater benefit from treatment with cobalt-chromium everolimus eluting stents with respect to cardiac death (fig $9 \Downarrow$, table $\mathrm{D}$ in appendix 1).

At sensitivity analysis, the occurrence of definite or probable stent thrombosis explained 47 (28.3\%) fatal cardiac events. After we censored these stent related events, the cardiac mortality rate was lower at $2.8 \%$ in the bare metal stent group and $2.1 \%$ in the cobalt-chromium everolimus eluting stent group, which is not a significant difference (hazard ratio $0.76,95 \%$ confidence interval 0.53 to $1.10 ; \mathrm{P}=0.15$ by multivariable $\mathrm{Cox}$ regression). After exclusion of the SPIRIT I study, the main outcome measure remained unchanged.

\section{Discussion}

Our combined analysis of data from individual patients, most of whom had acute coronary syndrome, from five randomised open label or single blinded trials in which events were independently and blinded adjudicated, shows that, compared with bare metal stents, cobalt-chromium everolimus eluting stent implantation is associated with a reduction in cardiac mortality. This benefit came with a significant reduction in myocardial infarction, fatal myocardial infarction, stent thrombosis, and target vessel revascularisation.

Randomised clinical trials provide the reference standard for comparing the effectiveness of treatments for a given clinical condition. Yet the effectiveness of treatments on relatively rare events, such as overall or cardiac mortality, might not be tested adequately in a single study because of limited statistical power. Combining individual patient data from multiple randomised trials helps to overcome this limitation by increasing the number of patients available for analysis, thus enhancing statistical power.

In particular, individual patient data meta-analyses are considered to be an ideal standard of systematic review as they have been shown to produce more reliable results. ${ }^{24}$ Compared with conventional meta-analyses that use aggregate data from publications, the availability of individual patient data allowed us to provide a more informative analysis of time dependent data derived from the whole period of follow-up with calculation of hazard ratios. Moreover, an individual patient data meta-analysis made possible an accurate definition of prespecified subgroup of patients, allowing for consistency assessment of study findings across predefined patient subgroups. Finally, it allowed us to investigate the effect of stent type on cardiac mortality after censoring specific fatal events related to stent or procedure, as well as assessing the robustness of our main study results by implementing both a multivariable and competing risk assessment analyses.

\section{Possible mechanisms}

To get some insights into the possible mechanism leading to a cardiac mortality benefit after cobalt-chromium everolimus eluting stent implantation, at sensitivity analysis we censored all cardiac fatalities temporarily associated (that is, occurring within one week) with the occurrence of definite or probable stent thrombosis. We chose a seven day time window to maximise specificity even if it is known to underestimate the actual burden of stent thrombosis in terms of cardiac fatalities. ${ }^{25}$ These events explained roughly a quarter of all cardiac fatalities observed up to two years. After we censored these stent related events, cardiac mortality was no longer different between the two stent groups, suggesting a mechanistic interpretation of our clinical observations. The lack of a significant difference in all cause mortality, despite the difference in cardiac mortality, is of interest. Crude non-cardiac mortality was $0.19 \%, 1.79 \%$, and $4.02 \%$ in first, second, and last third of the age distribution, respectively $(\mathrm{P}<0.001)$.

A potential diluting effect of benefit observed for cobalt-chromium everolimus eluting stent on all cause mortality could be ascribed to the higher non-cardiac mortality rate among older patients.

Treatment effect was not altered by other characteristics of patients, including sex, age, presence of diabetes, extension of coronary artery disease, the need for overlapping stents, use of glycoprotein IIb/IIIa inhibitors, treatment of left anterior descending artery, or duration of clopidogrel therapy after coronary stenting.

We found evidence of an interaction between treatment effect and stent type for the acuity of coronary artery disease, indicating that patients with stable coronary artery disease might have greater benefit from treatment with cobalt-chromium everolimus eluting stents in terms of cardiac mortality. This could be chance a finding, however, because of the small sample size of stable patients $(n=610)$ and the multiple explored subgroups (thereby inflating type I error). Further studies are warranted to verify this hypothesis.

\section{Comparison with other studies}

After the widespread use of first generation drug eluting stents in clinical practice, concern was raised that the reduction in restenosis associated with these stents was achieved at the cost of a potential increase in adverse clinical events, including death and myocardial infarction. ${ }^{26-28}$ Long term treatment with dual antiplatelets has been therefore advocated after implantation of drug eluting stents, ${ }^{29}$ despite the absence of supporting evidence. Considerable efforts have gone into the development of new generation drug eluting stents that would retain the powerful anti-restenosis properties of sirolimus and paclitaxel eluting stents, yet provide improved deliverability and regain safety profiles comparable with bare metal stents. ${ }^{30}$ 
Most randomised trials, however, have compared second generation drug eluting stents with their first generation counterparts, and rarely with bare metal stents, thus restricting a fully comparative understanding of their outcomes. No single study comparing drug eluting with bare metal stents or different types of drug eluting stents has ever been powered for mortality. Hence, the lack of evidence coming from a single, albeit relatively large, randomised controlled trial regarding the proposed association between stent thrombosis and mortality should be interpreted with the knowledge of the likelihood of type II error.

Recently, a network meta-analysis of 49 randomised trials, including 50844 patients, suggested that cobalt-chromium everolimus eluting stent was associated with a significant reduction of definite stent thrombosis during two years of follow-up compared with bare metal stent. ${ }^{31}$ That analysis, however, included only two direct randomised trials comparing cobalt-chromium everolimus eluting and bare metal stents, ${ }^{11}{ }^{12}$ and follow-up data for over a year were available for only one ${ }^{11}$ of these two studies. Therefore, this network meta-analysis fell short in dealing with the concern that very late stent thrombosis (that is, beyond one year) might counterweigh early reduction of thrombotic events. Notably this paradigm has also been observed in pooled analyses of first generation drug eluting versus bare metal stent. ${ }^{6}$ Different durations of dual antiplatelet therapy in patients treated with the two types of stent or differential use of antithrombotics at the time of intervention are also possible confounding factors in this study, which were not corrected for. ${ }^{31}$ Therefore, whether cobalt-chromium everolimus eluting stents would provide sustained improved safety over bare metal stents and most importantly to what extent this could translate into an improved survival rate remains so far largely elusive.

\section{Strengths and limitations}

Our pooled analysis of 4896 patients, most of whom had acute coronary syndrome, is the first to show a cardiac mortality benefit associated with the use of a specific second generation drug eluting stent-namely, cobalt-chromium everolimus eluting - compared with a bare metal stent. This treatment effect persisted after multivariable adjustment of confounders, including duration of dual antiplatelet therapy after stenting and use of glycoprotein IIb/IIIa inhibitors during the procedure.

Our observation that a durable polymer based drug eluting stent, such as the cobalt-chromium everolimus eluting stent, offers improved safety and efficacy profiles compared with non-active polymer-free stents supports a major paradigm shift in our understanding about coronary devices.

Firstly, stent safety and efficacy can no longer be disconnected at least for some newer generation devices. Two studies have so far randomised patients to first or second generation drug eluting stents, including cobalt-chromium everolimus eluting stent, to evaluate the optimal duration of treatment with clopidogrel. ${ }^{32}{ }^{33}$ These trials were largely underpowered to conclusively assess the optimal duration of treatment after each of the single stent to which patients have been randomised. Yet, a distinct signal towards a possible increase of ischaemic events after discontinuation of clopidogrel at six months has been specifically observed after sirolimus or paclitaxel eluting stents but not after cobalt-chromium everolimus eluting stents.

Additionally, because the durable polymer might not necessarily harbour potential for thrombogenesis, it does not need to be avoided in future. Recently, the rates of stent thrombosis were reduced with fluorinated polymer coated stents compared with equivalent bare metal stents in an experimental setting. ${ }^{34}$ Four out of the five studies included in our pooled analysis compared cobalt-chromium everolimus eluting stent with the uncoated otherwise identical metallic stent, and they showed a reduction in fatal and non-fatal adverse events consistent with the results of our pooled analysis. It is therefore conceivable to attribute the benefit for ischaemic events and cardiac mortality noted here and elsewhere to the presence of the fluorinated copolymer/drug coatings. Bare metal stent thrombogenicity has long been recognised. ${ }^{35}$ Copolymer coatings in cobalt-chromium everolimus eluting stent are durable because of the hydrophobic nature of fluorinated polymers, and they can act as a mechanical barrier excluding metallic surface potential for thrombogenesis. Moreover, fluorinated copolymer coatings are highly electronegative and as such repel protein adsorption because of their high electronegativity and elicit a cellular response conducive to healing with minimal chronic inflammation. ${ }^{36}$

No single study has so far suggested a safety issue through over three $^{37} 38$ or even five years ${ }^{39}$ after cobalt-chromium everolimus eluting stent implantation compared with first generation drug eluting stents. Longer duration follow-up is required to confirm the durability of the benefit observed here at a medium term time point when cobalt-chromium everolimus eluting stents are compared with bare metal stents.

Actual dual antiplatelet therapy status at follow-up was not ${ }^{11}$ or was suboptimally ${ }^{17}$ recorded in two of the five included studies. Hence, the role of concomitant antiplatelet therapy should be further explored, bearing in mind that no single study has so far reported a cardiac mortality benefit of clopidogrel therapy beyond one month. No detailed information is available from any of the included studies regarding patients who underwent surgery throughout follow-up.

While an explanation for the observed reduction in cardiac mortality in favour of cobalt-chromium everolimus eluting stent can be only speculative at the present time, an interplay between reduced device thrombegenicity as suggested by the lower stent thrombosis and myocardial infarction rates coupled with improved efficacy (that is, reduced need for target vessel reintervention because of neointimal proliferation) might account for the observed medium term cardiac survival benefit.

\section{Conclusions and policy implications}

This collaborative individual patient data meta-analysis of five randomised controlled trials, including 4896 patients most with acute coronary syndrome, shows a consistent reduction of several fatal and non-fatal ischaemic endpoints in favour of cobalt-chromium everolimus eluting stent compared with bare metal stents, including cardiac mortality, stent thrombosis (both definite and definite or probable), myocardial infarction, and target vessel revascularisation throughout two year follow-up. Our analysis challenges the current belief that bare metal stents are safer than drug eluting stents. Stent safety and efficacy can no longer be disconnected, at least for some newer generation devices.

Contributors: MV, MS, CK, JMDTH and ADB, acted as study principal investigators of PRODIGY, EXAMINATION, BASKET-PROVE and XIMA, respectively and co-wrote the manuscript together with PWS who acted as chairman of the EXAMINATION study and principal investigator of the SPIRIT I trial. MV and GF performed all statistical analyses, which were supervised by all other authors. All authors reviewed all the data and commented on the report.

Funding: This research received no specific grant from any funding agency in the public, commercial, or not-for-profit sectors. 


\section{What is already known on this topic}

Coronary stents are widely used to treat patients with coronary artery disease, with drug eluting stents being more efficacious than bare metal stents in preventing in stent restenosis and subsequent need for reintervention

As first generation drug eluting stents were associated with higher rates of stent thrombosis than bare metal stents, newer generation drug eluting stents were developed to improve the safety and main the efficacy

Most randomised trials compared newer generation drug eluting stents with first generation stents, and rarely with bare metal stents, restricting a fully comparative understanding of their outcomes

\section{What this study adds}

This individual patient data meta-analysis shows a consistent reduction of several fatal and non-fatal ischaemic endpoints in favour of the newer generation everolimus eluting stent compared with bare metal stents, including significant reductions of cardiac mortality, stent thrombosis, myocardial infarction, and target vessel revascularisation throughout two year follow-up

Competing interests: All authors have completed the ICMJE uniform disclosure form at www.icmje.org/coi_disclosure.pdf and declare that MV has received honorariums for lectures/advisory board from Abbott Vascular and that MS, AC, and SG have received honorariums for lectures/advisory board and research grant from Abbott Vascular.

\section{Ethical approval: Not required.}

Data sharing: No additional data available.

Declaration of transparency: The lead author (the manuscript's guarantor) affirms that the manuscript is an honest, accurate, and transparent account of the study being reported; that no important aspects of the study have been omitted; and that any discrepancies from the study as planned (and, if relevant, registered) have been explained.

1 Stone GW, Ellis SG, Cox DA, Hermiller J, O'Shaughnessy C, Mann JT, et al. A polymer-based, paclitaxel-eluting stent in patients with coronary artery disease. N Eng J Med 2004;350:221-31

2 Valgimigli M, Campo G, Percoco G, Bolognese L, Vassanelli C, Colangelo S, et al. Comparison of angioplasty with infusion of tirofiban or abciximab and with implantation of sirolimus-eluting or uncoated stents for acute myocardial infarction: the MULTISTRATEGY randomized trial. JAMA 2008;299:1788-99.

3 Kastrati A, Mehilli J, Pache J, Kaiser C, Valgimigli M, Kelbaek H, et al. Analysis of 14 trials comparing sirolimus-eluting stents with bare-metal stents. N Engl J Med 2007;356:1030-9.

4 Tu JV, Bowen J, Chiu M, Ko DT, Austin PC, He Y, et al. Effectiveness and safety of drug-eluting stents in Ontario. N Engl J Med 2007;357:1393-402.

5 Eisenstein EL, Anstrom KJ, Kong DF, Shaw LK, Tuttle RH, Mark DB, et al. Clopidogrel use and long-term clinical outcomes after drug-eluting stent implantation. JAMA 2007;297:159-68.

6 Kalesan B, Pilgrim T, Heinimann K, Raber L, Stefanini GG, Valgimigli M, et al. Comparison of drug-eluting stents with bare metal stents in patients with ST-segment elevation myocardial infarction. Eur Heart J 2012;33:977-87.

7 Kedhi E, Joesoef KS, McFadden E, Wassing J, van Mieghem C, Goedhart D, et al. Second-generation everolimus-eluting and paclitaxel-eluting stents in real-life practice (COMPARE): a randomised trial. Lancet 2010;375:201-9.

8 Stone GW, Midei M, Newman W, Sanz M, Hermiller JB, Williams J, et al. Comparison of an everolimus-eluting stent and a paclitaxel-eluting stent in patients with coronary artery disease: a randomized trial. JAMA 2008:299:1903-13.

9 Stone GW, Rizvi A, Newman W, Mastali K, Wang JC, Caputo R, et al. Everolimus-eluting versus paclitaxel-eluting stents in coronary artery disease. N Engl J Med 2010;362:1663-74.

10 Serruys PW, Silber S, Garg S, van Geuns RJ, Richardt G, Buszman PE, et al. Comparison of zotarolimus-eluting and everolimus-eluting coronary stents. N Engl J Med 2010;363:136-46.

11 Kaiser $\mathrm{C}$, Galatius $\mathrm{S}$, Erne $\mathrm{P}$, Eberli F, Alber $\mathrm{H}$, Rickli $\mathrm{H}$, et al. Drug-eluting versus bare-metal stents in large coronary arteries. N Engl J Med 2010;363:2310-9.

12 Sabate M, Cequier A, Iniguez A, Serra A, Hernandez-Antolin R, Mainar V, et al. Everolimus-eluting stent versus bare-metal stent in ST-segment elevation myocardial infarction (EXAMINATION): 1 year results of a randomised controlled trial. Lancet 2012;380:1482-90

13 Valgimigli M, Tebaldi M, Borghesi M, Vranckx P, Campo G, Tumscitz C, et al. Two-year outcomes after first- or second-generation drug-eluting or bare-metal stent implantation in all-comer patients undergoing percutaneous coronary intervention: a pre-specified analysis from the prolonging dual antiplatelet treatment after grading stent-induced intimal hyperplasia study (PRODIGY). JACC Cardiovasc Interv 2014;7:20-8.

14 Higgins JP, Altman DG, Sterne JAC, eds. Chapter 8: Assessing risk of bias in included studies. In: Higgins JPT, Green S, eds. Cochrane handbook for systematic reviews, version 5.1.0 (updated March 2011). Cochrane Collaboration, 2011. www.cochranehandbook.org.

15 Liberati A, Altman DG, Tetzlaff J, Mulrow C, Gotzsche PC, loannidis JP, et al. The PRISMA statement for reporting systematic reviews and meta-analyses of studies that evaluate healthcare interventions: explanation and elaboration. BMJ 2009;339:b2700.

16 Cutlip DE, Windecker S, Mehran R, Boam A, Cohen DJ, van Es GA, et al. Clinical end points in coronary stent trials: a case for standardized definitions. Circulation 2007:115:2344-51.

17 De Belder A, de la Torre Hernandez JM, Lopez-Palop R, O'Kane P, Hernandez F, Strange $\mathrm{J}$, et al. A prospective randomized trial of everolimus-eluting stents versus bare metal stents in octogenarians: Xience or Vision stents for the management of angina in the elderly—the Xima Trial. J Am Coll Cardiol 2013;63:1371-5.
18 Sabate M, Brugaletta S, Cequier A, Iniguez A, Serra A, Hernadez-Antolin R, et al. The EXAMINATION Trial (everolimus-eluting stents versus bare-metal stents in st-segment elevation myocardial infarction): 2-year results from a multicenter randomized controlled trial. JACC Cardiovasc Interv 2014;7:64-71.

19 Valgimigli M, Campo G, Percoco G, Monti M, Ferrari F, Tumscitz C, et al. Randomized comparison of 6-versus 24 -month clopidogrel therapy after balancing anti-intimal hyperplasia stent potency in all-comer patients undergoing percutaneous coronary intervention design and rationale for the prolonging dual-antiplatelet treatment after grading stent-induced intimal hyperplasia study (PRODIGY). Am Heart J 2010;160:804-11.

20 Beijk MA, Neumann FJ, Wiemer M, Grube E, Haase J, Thuesen L, et al. Two-year results of a durable polymer everolimus-eluting stent in de novo coronary artery stenosis (the SPIRIT FIRST Trial). Eurolntervention 2007;3:206-12.

21 Therneau TM, Grambsch PM, Pankratz VS. Penalized survival models and frailty. J Comput Graph Stat 2003;12:156-75.

22 Fine JP, Gray RJ. A proportional hazards model for the subdistribution of a competing risk. J Am Stat Assoc 1999;94:496-509.

23 Higgins JP, Thompson SG, Deeks JJ, Altman DG. Measuring inconsistency in meta-analyses. BMJ 2003;327:557-60.

24 Stewart LA, Tierney JF. To IPD or not to IPD? Advantages and disadvantages of systematic reviews using individual patient data. Eval Health Prof 2002;25:76-97.

25 De la Torre-Hernandez JM, Alfonso F, Hernandez F, Elizaga J, Sanmartin M, Pinar E, et al. Drug-eluting stent thrombosis: results from the multicenter Spanish registry ESTROFA (Estudio ESpanol sobre TROmbosis de stents FArmacoactivos). J Am Coll Cardiol 2008;51:986-90.

26 Serruys PW, Kutryk MJ, Ong AT. Coronary-artery stents. N Eng/ J Med 2006;354:483-95.

27 Camenzind E, Steg PG, Wijns W. Stent thrombosis late after implantation of first-generation drug-eluting stents: a cause for concern. Circulation 2007;115:1440-55

28 Luscher TF, Steffel J, Eberli FR, Joner M, Nakazawa G, Tanner FC, et al. Drug-eluting stent and coronary thrombosis: biological mechanisms and clinical implications. Circulation 2007;115:1051-8

29 King SB 3rd, Smith SC Jr, Hirshfeld JW Jr, Jacobs AK, Morrison DA, Williams DO, et al. 2007 focused update of the ACC/AHA/SCAI 2005 guideline update for percutaneous coronary intervention: a report of the American College of Cardiology/American Heart Association Task Force on Practice guidelines. J Am Coll Cardiol 2008;51:172-209.

30 Stefanini GG, Holmes DR Jr. Drug-eluting coronary-artery stents. N Engl J Med 2013;368:254-65

31 Palmerini T, Biondi-Zoccai G, Della Riva D, Stettler C, Sangiorgi D, D'Ascenzo F, et al. Stent thrombosis with drug-eluting and bare-metal stents: evidence from a comprehensive network meta-analysis. Lancet 2012;379:1393-402.

32 Valgimigli M, Borghesi M, Tebaldi M, Vranckx P, Parrinello G, Ferrari R. Should duration of dual antiplatelet therapy depend on the type and/or potency of implanted stent? A pre-specified analysis from the prolonging dual antiplatelet treatment after grading stent-induced intimal hyperplasia study (PRODIGY). Eur Heart J 2013;34:909-19.

33 Gwon HC, Hahn JY, Park KW, Song YB, Chae IH, Lim DS, et al. Six-month versus 12-month dual antiplatelet therapy after implantation of drug-eluting stents: the efficacy of Xience/Promus versus Cypher to reduce late loss after stenting (EXCELLENT) randomized, multicenter study. Circulation 2011;125:505-13.

34 Kolandaivelu K, Swaminathan R, Gibson WJ, Kolachalama VB, Nguyen-Ehrenreich KL, Giddings VL, et al. Stent thrombogenicity early in high-risk interventional settings is driven by stent design and deployment and protected by polymer-drug coatings. Circulation 2011;123:1400-9.

35 Rogers C, Edelman ER. Endovascular stent design dictates experimental restenosis and thrombosis. Circulation 1995;91:2995-3001.

36 Xie X, Guidoin R, Nutley M, Zhang Z. Fluoropassivation and gelatin sealing of polyester arterial prostheses to skip preclotting and constrain the chronic inflammatory response. J Biomed Mater Res B Appl Biomater 2010;93:497-509.

37 Brener SJ, Kereiakes DJ, Simonton CA, Rizvi A, Newman W, Mastali K, et al. Everolimus-eluting stents in patients undergoing percutaneous coronary intervention: final 3-year results of the clinical evaluation of the XIENCE V Everolimus eluting coronary stent system in the treatment of subjects with de novo native coronary artery lesions trial. $A m$ Heart J 2013;166:1035-42.

38 Raber L, Juni P, Nuesch E, Kalesan B, Wenaweser P, Moschovitis A, et al. Long-term comparison of everolimus-eluting and sirolimus-eluting stents for coronary revascularization. J Am Coll Cardiol 2011:57:2143-51.

39 Gada H, Kirtane AJ, Newman W, Sanz M, Hermiller JB, Mahaffey KW, et al. 5-Yea Results of a randomized comparison of XIENCE $V$ everolimus-eluting and TAXUS paclitaxel-eluting stents: final results from the SPIRIT III trial (clinical evaluation of the XIENCE V everolimus eluting coronary stent system in the treatment of patients with de novo native coronary artery lesions). JACC Cardiovasc Interv 2013;6:1263-6.

Accepted: 08 October 2014

Cite this as: $B M J 2014 ; 349: 96427$ 
This is an Open Access article distributed in accordance with the Creative Commons Attribution Non Commercial (CC BY-NC 4.0) license, which permits others to distribute, remix, adapt, build upon this work non-commercially, and license their derivative works on different terms, provided the original work is properly cited and the use is non-commercial. See: http://creativecommons.org/licenses/by-nc/4.0/. 


\section{Tables}

Table 1/ Clinical characteristics in $\mathbf{4 8 9 6}$ patients in five trials in meta-analysis of effects of bare metal stent (BMS) or cobalt-chromium everolimus eluting stents (DES) on fatal and non-fatal cardiovascular events. Figures are numbers (percentages) unless stated otherwise

\begin{tabular}{|c|c|c|c|c|c|c|c|c|c|c|c|}
\hline & \multirow[b]{2}{*}{$\begin{array}{c}\text { Overall } \\
(n=4896)\end{array}$} & \multicolumn{2}{|c|}{ PRODIGY } & \multicolumn{2}{|c|}{ EXAMINATION } & \multicolumn{2}{|c|}{ BASKET PROVE } & \multicolumn{2}{|c|}{ SPIRIT I } & \multicolumn{2}{|c|}{ XIMA } \\
\hline & & $\begin{array}{c}\text { BMS } \\
(n=502)\end{array}$ & $\begin{array}{c}\text { DES } \\
(n=501)\end{array}$ & $\begin{array}{c}\text { BMS } \\
(\mathrm{n}=747)\end{array}$ & $\begin{array}{c}\text { DES } \\
(n=751)\end{array}$ & $\begin{array}{c}\text { BMS } \\
(n=765)\end{array}$ & $\begin{array}{c}\text { DES } \\
(\mathrm{n}=774)\end{array}$ & $\begin{array}{c}\text { BMS } \\
(\mathrm{n}=29)\end{array}$ & $\begin{array}{c}\text { DES } \\
(n=27)\end{array}$ & $\begin{array}{c}\text { BMS } \\
(\mathrm{n}=401)\end{array}$ & $\begin{array}{c}\text { DES } \\
(n=399)\end{array}$ \\
\hline Mean (SD) age (years) & $67(13)$ & $68.9(11.2)$ & $68.1(11.3)$ & $61.6(12.6)$ & $60.8(12.2)$ & $64.1(10.8)$ & $63.6(10.7)$ & $\begin{array}{l}61.4 \\
(9.3) \\
\end{array}$ & $\begin{array}{l}64.2 \\
(9.6) \\
\end{array}$ & $83.4(3.1)$ & $83.6(3.2)$ \\
\hline Female & $\begin{array}{l}1200 \\
(24.5)\end{array}$ & $139(27.7)$ & $107(21.4)$ & $137(18.3)$ & $117(15.6)$ & $179(23.4)$ & $187(24.2)$ & $7(24.1)$ & $8(29.6)$ & $164(40.9)$ & $155(38.8)$ \\
\hline Diabetes & $914(18.7)$ & $111(22.1)$ & $113(22.5)$ & $121(16.2)$ & $137(18.3)$ & $108(14.1)$ & $119(15.4)$ & $3(10.3)$ & $3(11.1)$ & $97(24.2)$ & $102(25.6)$ \\
\hline \multicolumn{12}{|l|}{ Smoking habit: } \\
\hline Current smoker & $\begin{array}{l}1581 \\
(32.3)\end{array}$ & $126(25.2)$ & $117(23.4)$ & $386(51.7)$ & $372(49.6)$ & $261(34.1)$ & $267(34.5)$ & $9(31.0)$ & $7(25.9)$ & $16(3.9)$ & $20(5.0)$ \\
\hline Former smoker & $\begin{array}{l}1323 \\
(27.0)\end{array}$ & $101(20.2)$ & $124(24.8)$ & $152(20.3)$ & $172(22.9)$ & $203(26.5)$ & $229(29.6)$ & $7(24.1)$ & $2(7.4)$ & $168(41.9)$ & $165(41.3)$ \\
\hline Never & $\begin{array}{c}1987 \\
(40.6)\end{array}$ & $272(54.5)$ & $259(51.8)$ & $209(27.9)$ & $206(27.5)$ & 301 (39.3) & 278 (35.9) & $13(44.8)$ & $18(66.7)$ & $217(54.1)$ & 214 (53.6) \\
\hline Hypertension & $\begin{array}{l}3055 \\
(62.4)\end{array}$ & $376(74.9)$ & $356(71.1)$ & $378(50.6)$ & $347(46.3)$ & $485(63.4)$ & $469(60.6)$ & $15(51.7)$ & $19(70.4)$ & $311(77.6)$ & $299(75.1)$ \\
\hline Hypercholesterolaemia & $\begin{array}{l}2680 \\
(54.7)\end{array}$ & 254 (50.6) & $294(58.7)$ & $301(40.3)$ & $354(47.2)$ & $495(64.7)$ & $498(64.3)$ & $22(75.9)$ & $20(70.1)$ & $212(52.9)$ & $230(57.6)$ \\
\hline Previous MI & $724(14.8)$ & $114(22.8)$ & $143(28.7)$ & $47(6.3)$ & $33(4.4)$ & $100(13.1)$ & $82(10.6)$ & 0 & 0 & $86(21.5)$ & $119(29.8)$ \\
\hline Previous CABG & $201(4.1)$ & $45(8.9)$ & $61(12.2)$ & $7(0.9)$ & $3(0.4)$ & $20(2.6)$ & $20(2.6)$ & 0 & 0 & $17(4.2)$ & $28(7.0)$ \\
\hline
\end{tabular}

$\mathrm{Ml}=$ myocardial infarction; $\mathrm{CABG}=$ coronary artery bypass grafting 
Table 2| Clinical presentation and treatment in 4896 patients in five trials in meta-analysis of effects of bare metal stent (BMS) or cobalt-chromium everolimus eluting (DES) on fatal and non-fatal cardiovascular events. Figures are numbers (percentages) unless stated otherwise

\begin{tabular}{|c|c|c|c|c|c|c|c|c|c|c|c|}
\hline & \multirow[b]{2}{*}{$\begin{array}{c}\text { Overall } \\
(n=4896)\end{array}$} & \multicolumn{2}{|c|}{ PRODIGY } & \multicolumn{2}{|c|}{ EXAMINATION } & \multicolumn{2}{|c|}{ BASKET PROVE } & \multicolumn{2}{|c|}{ SPIRIT I } & \multicolumn{2}{|c|}{ XIMA } \\
\hline & & $\begin{array}{c}\text { BMS } \\
(n=502)\end{array}$ & $\begin{array}{c}\text { DES } \\
(n=501)\end{array}$ & $\begin{array}{c}\text { BMS } \\
(n=747)\end{array}$ & $\begin{array}{c}\text { DES } \\
(n=751)\end{array}$ & $\begin{array}{c}\text { BMS } \\
(n=765)\end{array}$ & $\begin{array}{c}\text { DES } \\
(n=774)\end{array}$ & $\begin{array}{l}\text { BMS } \\
(n=29)\end{array}$ & $\begin{array}{c}\text { DES } \\
(n=27)\end{array}$ & $\begin{array}{c}\text { BMS } \\
(n=401)\end{array}$ & $\begin{array}{c}\text { DES } \\
(n=399)\end{array}$ \\
\hline $\begin{array}{l}\text { Stable angina } \\
\text { pectoris }\end{array}$ & $615(15.6)$ & $111(22.1)$ & $118(23.6)$ & 0 & 0 & $34(4.4)$ & $41(5.3)$ & $29(100)$ & $27(100)$ & $127(31.7)$ & $128(32.2)$ \\
\hline \multicolumn{12}{|c|}{ Acute coronary syndrome (ACS): } \\
\hline $\begin{array}{l}\text { Non-ST } \\
\text { elevation ACS }\end{array}$ & $2150(43.9)$ & $211(42.0)$ & $220(43.9)$ & 0 & 0 & $615(80.4)$ & 619 (79.9) & 0 & 0 & $237(59.2)$ & $248(62.3)$ \\
\hline $\begin{array}{l}\text { ST segment } \\
\text { elevation MI }\end{array}$ & $2129(43.5)$ & $180(35.9)$ & $163(32.5)$ & $747(100)$ & $751(100)$ & $116(15.1)$ & $114(14.7)$ & 0 & 0 & $36(9.0)$ & $22(5.5)$ \\
\hline \multicolumn{12}{|c|}{ Angiographic features: } \\
\hline $\begin{array}{l}\text { Single vessel } \\
\text { disease }\end{array}$ & $2795(57.1)$ & $170(33.9)$ & $145(28.9)$ & $653(87.4)$ & $634(84.4)$ & $438(57.2)$ & $455(58.8)$ & $\begin{array}{c}23 \\
(79.3) \\
\end{array}$ & $\begin{array}{c}20 \\
(74.1) \\
\end{array}$ & $127(31.7)$ & $130(32.6)$ \\
\hline $\begin{array}{l}\text { Multi-vessel } \\
\text { disease }\end{array}$ & $2096(42.8)$ & $332(66.1)$ & $356(71.1)$ & $94(12.6)$ & $117(15.6)$ & $327(42.7)$ & $319(41.2)$ & $6(20.7)$ & 7 (25.9) & $270(67.3)$ & $268(67.2)$ \\
\hline $\begin{array}{l}\text { LAD/LMCA } \\
\text { treated }\end{array}$ & $2523(51.5)$ & $287(57.2)$ & $260(51.9)$ & $309(41.4)$ & $326(43.4)$ & $404(52.8)$ & $417(53.9)$ & $\begin{array}{c}13 \\
(44.8) \\
\end{array}$ & $\begin{array}{c}13 \\
(48.1) \\
\end{array}$ & $248(61.8)$ & $246(246)$ \\
\hline CFX treated & 1155 (23.6) & $147(29.3)$ & $186(37.1)$ & $107(14.3)$ & $102(13.6)$ & $203(26.5)$ & $202(26.1)$ & $6(20.7)$ & $6(22.2)$ & $97(24.2)$ & $99(24.8)$ \\
\hline $\mathrm{RCA}$ treated & 1934 (39.5) & $190(37.8)$ & $177(35.3)$ & $329(44.0)$ & $322(42.9)$ & $325(42.5)$ & $310(40.0)$ & $\begin{array}{c}10 \\
(34.5) \\
\end{array}$ & $8(29.6)$ & $131(32.7)$ & $132(33.1)$ \\
\hline $\begin{array}{l}\text { No of treated } \\
\text { lesions }\end{array}$ & $1.3(0.69)$ & $1.5(0.8)$ & $1.5(0.9)$ & $1.1(0.3)$ & $1.2(0.4)$ & $1.5(0.8)$ & $1.4(0.8)$ & 1 & 1 & $1.4(0.6)$ & $1.4(0.6)$ \\
\hline $\begin{array}{l}\text { No of stents } \\
\text { implanted }\end{array}$ & $1.6(1.0)$ & $1.8(1.1)$ & $1.9(1.2)$ & $1.5(0.7)$ & $1.5(0.8)$ & $1.7(1.1)$ & $1.7(1.1)$ & 1 & 1 & $1.6(1.1)$ & $1.6(1.1)$ \\
\hline $\begin{array}{l}\text { Total stent } \\
\text { length }(\mathrm{mm}) \\
\end{array}$ & $30.9(22.2)$ & $36.9(30.1)$ & $39.6(28.3)$ & $27.0(13.2)$ & $27.9(14.8)$ & $31.1(22.5)$ & 31.1 (23.3) & 18 & 18 & $29.1(20.6)$ & 28.5 (22.9) \\
\hline Stent size (mm) & $3.2(0.4)$ & $2.9(0.5)$ & $2.9(0.5)$ & $3.2(0.4)$ & $3.2(0.4)$ & $3.5(0.3)$ & $3.5(0.4)$ & 3 & 3 & $2.9(0.3)$ & $2.9(0.3)$ \\
\hline $\begin{array}{l}\text { Overlapping } \\
\text { stents }\end{array}$ & 1149 (23.5) & $139(27.7)$ & $142(28.3)$ & $206(27.6)$ & $198(26.4)$ & $150(19.6)$ & $155(20.0)$ & 0 & 0 & $84(20.9)$ & 75 (18.8) \\
\hline $\begin{array}{l}\text { Use of Ilb/IIla } \\
\text { inhibitors }\end{array}$ & $1652(33.8)$ & $232(46.2)$ & $219(43.7)$ & $385(51.5)$ & $400(53.3)$ & $168(21.9)$ & $176(22.7)$ & $1(3.4)$ & $2(7.4)$ & $37(9.4)$ & $32(8.1)$ \\
\hline $\begin{array}{l}\text { No of patients } \\
\text { who continued } \\
\text { DAPT beyond } \\
\text { one year }\end{array}$ & 707 (14.4) & $230(46.1)$ & $258(51.6)$ & $98(13.1)$ & $115(15.3)$ & 0 & 0 & $4(13.8)$ & $2(7.4)$ & 0 & 0 \\
\hline
\end{tabular}

$\mathrm{DAPT}=$ dual antiplatelet therapy; $\mathrm{Ml}=$ myocardial infarction; $\mathrm{RCA}=$ right coronary artery; $\mathrm{CFX}=$ circumflex artery; LAD=left anterior descending artery; LMCA=left main coronary artery. 
Table 3| Recommended duration (months) of dual antiplatelet therapy and follow-up treatment in three of five trials in meta-analysis of effects of bare metal stent (BMS) or cobalt-chromium everolimus eluting (DES) on fatal and non-fatal cardiovascular events

PRODIGY $(n=1003)$ EXAMINATION $(n=1498)$ BASKET PROVE $(n=1539)$ SPIRIT I $(n=56)$ XIMA $(n=800)$

\begin{tabular}{lccccc} 
Experimental arm & 6 or $24^{*}$ & 12 & 12 & $\geq 3$ & 12 \\
\hline Control arm & Up to 6 or $24^{*}$ & 12 & 12 & $\geq 3$ & 3 \\
\hline Follow-up (years) & 2 & 2 & 2 & 5 & 1 \\
\hline
\end{tabular}

${ }^{*} 1: 1$ randomisation. 
Table 4| Overall clinical outcomes in 4896 patients in five trials in meta-analysis by treatment assignment to bare metal stent (BMS) or cobalt chromium-everolimus eluting stent (DES). Figures are numbers (percentage) of patients and hazard ratios (HR) from multivariable Cox regression stratified by trial

\begin{tabular}{|c|c|c|c|c|c|c|}
\hline \multirow[b]{2}{*}{ Outcomes } & \multicolumn{2}{|c|}{ Event rate } & \multicolumn{2}{|c|}{ Unadjusted } & \multicolumn{2}{|c|}{ Adjusted $^{*}$} \\
\hline & BMS $(n=2444)$ & DES $(n=2452)$ & HR (95\% Cl) & $P$ value & HR (95\% Cl) & $P$ value \\
\hline Cardiac death & $99(4.1)$ & $67(2.7)$ & 0.67 (0.49 to 0.91$)$ & 0.01 & $0.69(0.50$ to 0.94$)$ & 0.02 \\
\hline Death from any cause & $144(5.9)$ & $121(4.9)$ & $0.83(0.65$ to 1.06$)$ & 0.14 & 0.84 (0.66 to 1.07$)$ & 0.16 \\
\hline \multicolumn{7}{|l|}{ Myocardial infarction: } \\
\hline All & $136(5.6)$ & $98(4.0)$ & 0.71 (0.55 to 0.92$)$ & 0.01 & $0.71(0.55$ to 0.93$)$ & 0.01 \\
\hline Non-fatal & $118(4.8)$ & $96(3.9)$ & 0.81 (0.61 to 1.05$)$ & 0.12 & $0.80(0.61$ to 1.05$)$ & 0.12 \\
\hline Fatal & $18(0.8)$ & $2(0.1)$ & 0.11 (0.03 to 0.48$)$ & 0.003 & 0.11 (0.03 to 0.49$)$ & 0.004 \\
\hline Definite stent thrombosis & $33(1.4)$ & $14(0.6)$ & $0.42(0.22$ to 0.78$)$ & 0.006 & 0.41 (0.22 to 0.76$)$ & 0.005 \\
\hline $\begin{array}{l}\text { Definite or probable stent } \\
\text { thrombosis }\end{array}$ & $63(2.6)$ & $31(1.3)$ & 0.48 (0.31 to 0.74$)$ & 0.001 & 0.48 (0.31 to 0.73$)$ & 0.001 \\
\hline $\begin{array}{l}\text { Target vessel } \\
\text { revascularisation }\end{array}$ & $250(10.2)$ & $105(4.3)$ & 0.29 (0.20 to 0.42$)$ & $<0.001$ & $0.29(0.20$ to 0.41$)$ & $<0.001$ \\
\hline $\begin{array}{l}\text { Target vessel myocardial } \\
\text { infarction }\end{array}$ & $44(1.8)$ & $22(0.9)$ & 0.27 (0.12 to 0.58$)$ & 0.001 & $0.27(0.12$ to 0.59$)$ & 0.001 \\
\hline $\begin{array}{l}\text { Cardiac death or } \\
\text { myocardial infarction }\end{array}$ & $207(8.5)$ & $156(6.4)$ & 0.75 (0.61 to 0.92$)$ & 0.006 & 0.76 (0.61 to 0.93$)$ & 0.008 \\
\hline $\begin{array}{l}\text { Death or myocardial } \\
\text { infarction }\end{array}$ & $250(10.2)$ & $206(8.4)$ & 0.81 (0.68 to 0.98$)$ & 0.028 & 0.81 (0.68 to 0.98$)$ & 0.03 \\
\hline
\end{tabular}

*Adjusted for clinical syndrome (that is, acute coronary syndrome $v$ stable syndrome), history of diabetes mellitus, female sex, use of glycoprotein Ilb/llla inhibitors, and up to 1 year $v$ longer duration of dual antiplatelet therapy. 


\section{Figures}

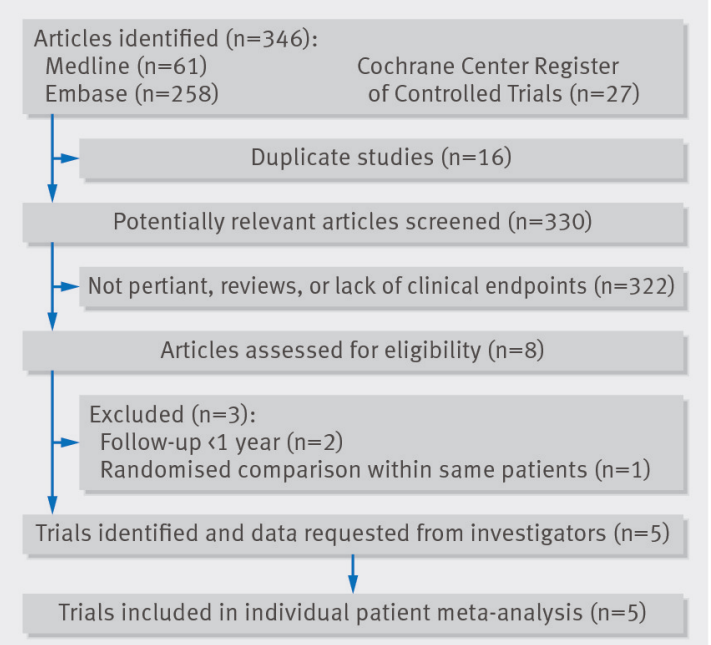

Fig 1 Flow diagram of literature search for studies included in meta-analysis

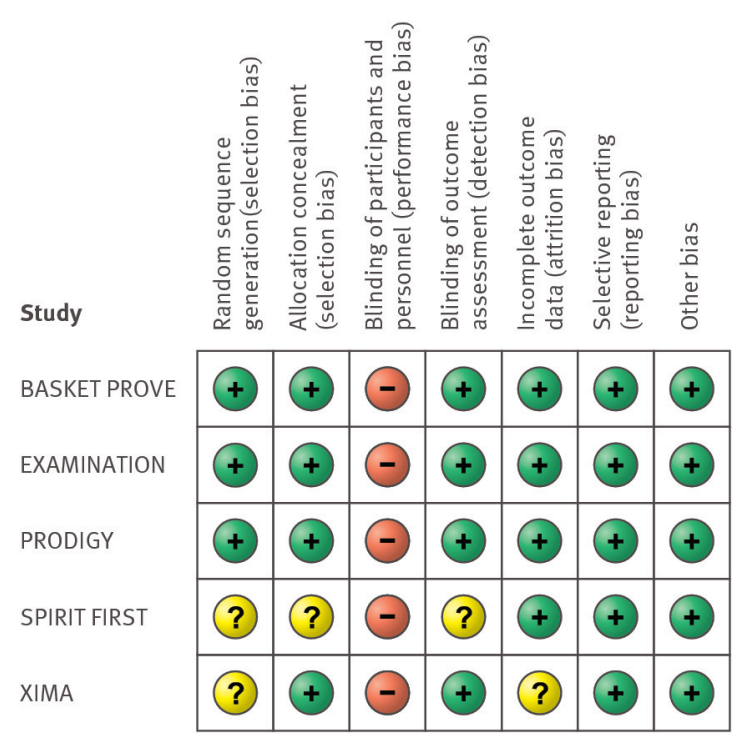

$\uparrow$ Low risk of bias (?) Unclear risk of bias $\odot$ High risk of bias

Fig 2 Risk of bias summary reporting each risk of bias item for each included study 

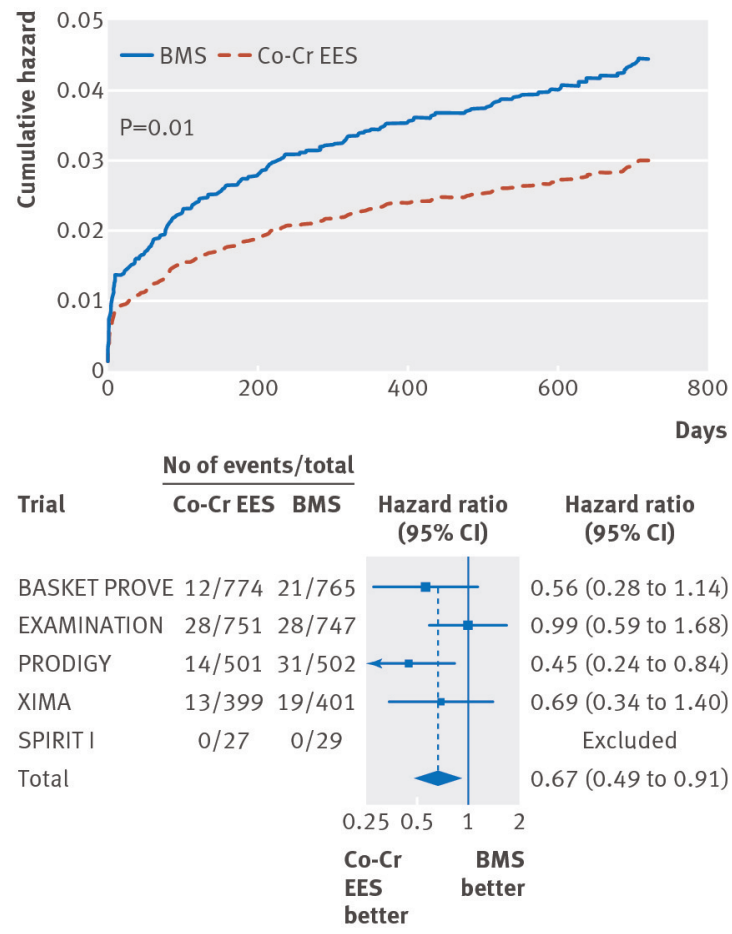

Fig 3 Cumulative hazard for cardiac death and forest plot with point estimates and $95 \%$ confidence intervals for each included study and pooled estimate from simple Cox regression model stratified by trial with random effects. Co-Cr EES=cobalt-chromium everolimus eluting; BMS=bare metal stent
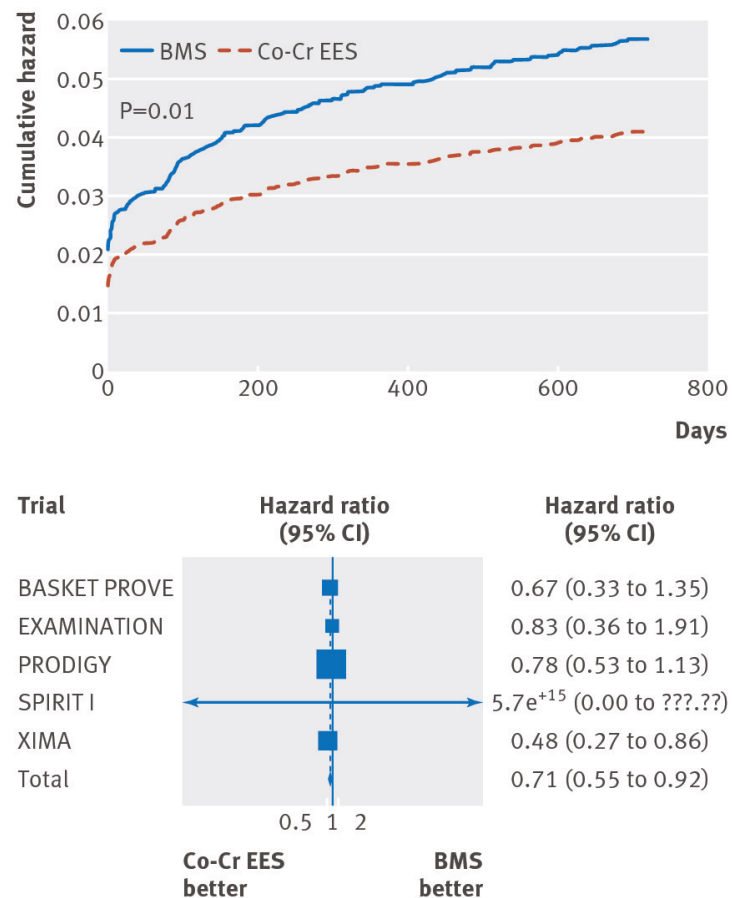

Fig 4 Cumulative incidence curve for myocardial infarction and forest plot with point estimates and 95\% confidence intervals for each included study and pooled estimate from simple Cox regression model stratified by trial with random effects. Co-Cr EES=cobalt-chromium everolimus eluting; $B M S=$ bare metal stent 

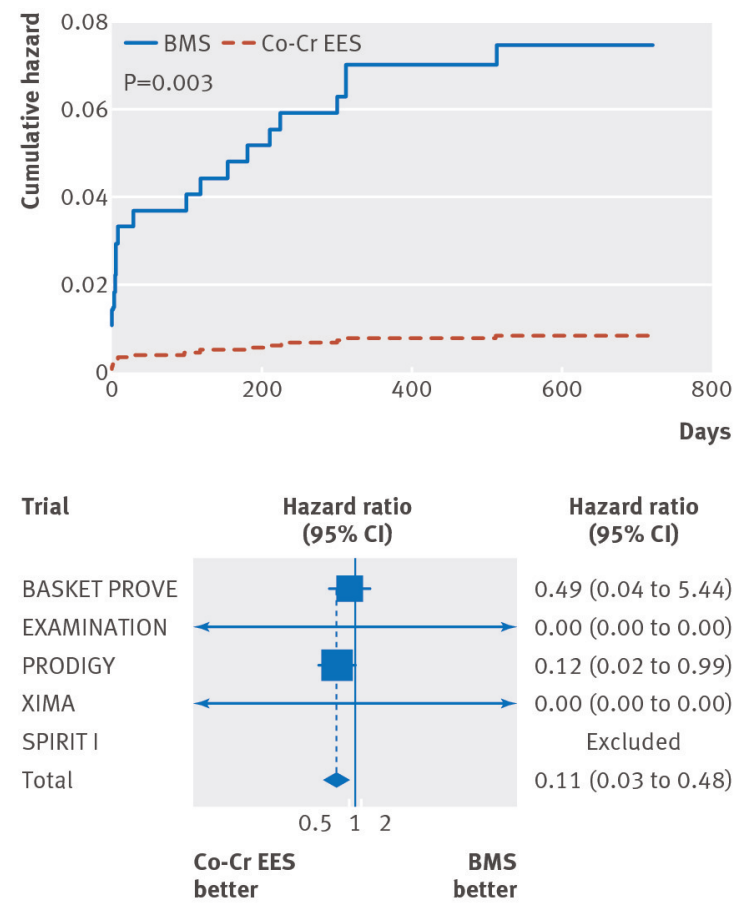

Fig 5 Cumulative incidence curve for fatal myocardial infarction and forest plot with point estimates and $95 \%$ confidence interval for each included study and pooled estimate from simple Cox regression model stratified by trial with random effects. Co-Cr EES=cobalt-chromium everolimus eluting; BMS=bare metal stent
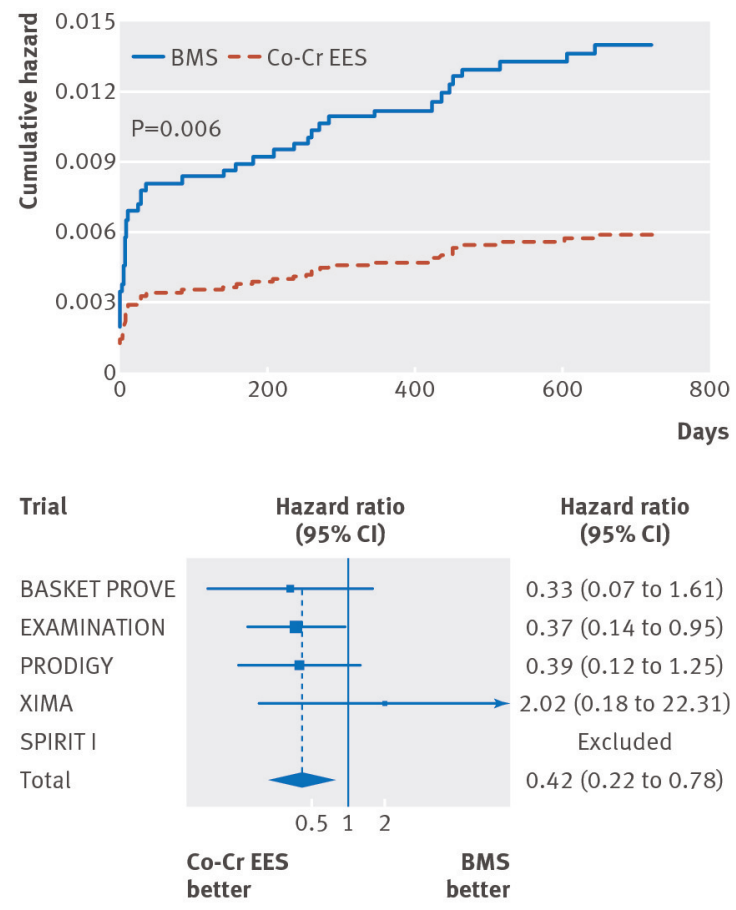

Fig 6 Cumulative incidence curve for definite stent thrombosis and forest plot with point estimates and 95\% confidence interval for each included study and pooled estimate from simple Cox regression model stratified by trial with random effects. Co-Cr EES=cobalt-chromium everolimus eluting; BMS=bare metal stent 

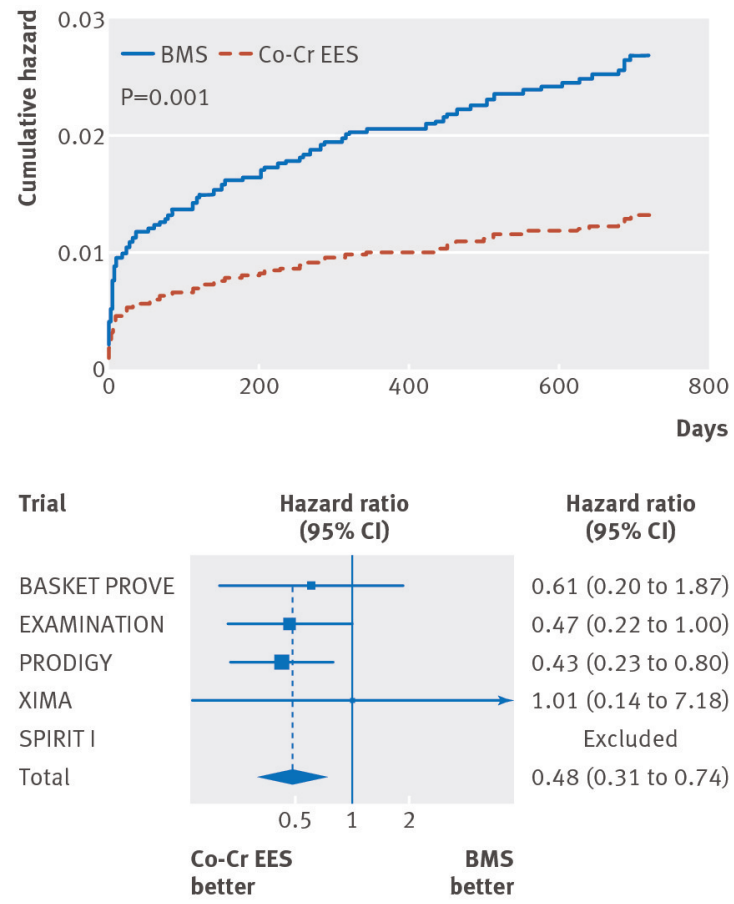

Fig 7 Cumulative incidence curve for definite or probable stent thrombosis and forest plot with point estimates and $95 \%$ confidence interval for each included study and pooled estimate from simple Cox regression model stratified by trial with random effects. Co-Cr EES=cobalt-chromium everolimus eluting; BMS=bare metal stent
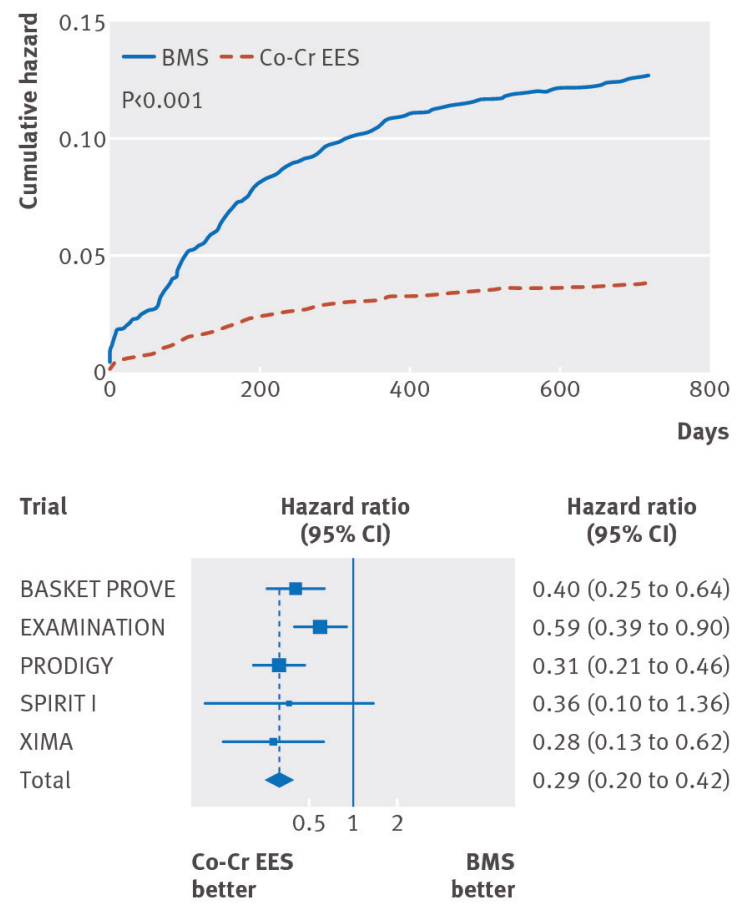

Fig 8 Cumulative incidence curve for target vessel revascularisation and forest plot with point estimates and $95 \%$ confidence interval for each included study and pooled estimate from simple Cox regression model stratified by trial with random effects. Co-Cr EES=cobalt-chromium everolimus eluting; BMS=bare metal stent 


Men
Women
Age $\geq 65$
Age $<65$
Diabetes
No diabetes
Acute coronary syndrome
Stable angina
Multi-vessel disease
No multi-vessel disease
Overlapping stent
No overlapping stent
Left anterior descending artery disease
No left anterior descending artery disease
Duel antiplatelet $>1$ year
Duel antiplatelet $\leq 1$ year
Ilb-IIla use
No Ilb-Illa use

No Ilb-Illa use

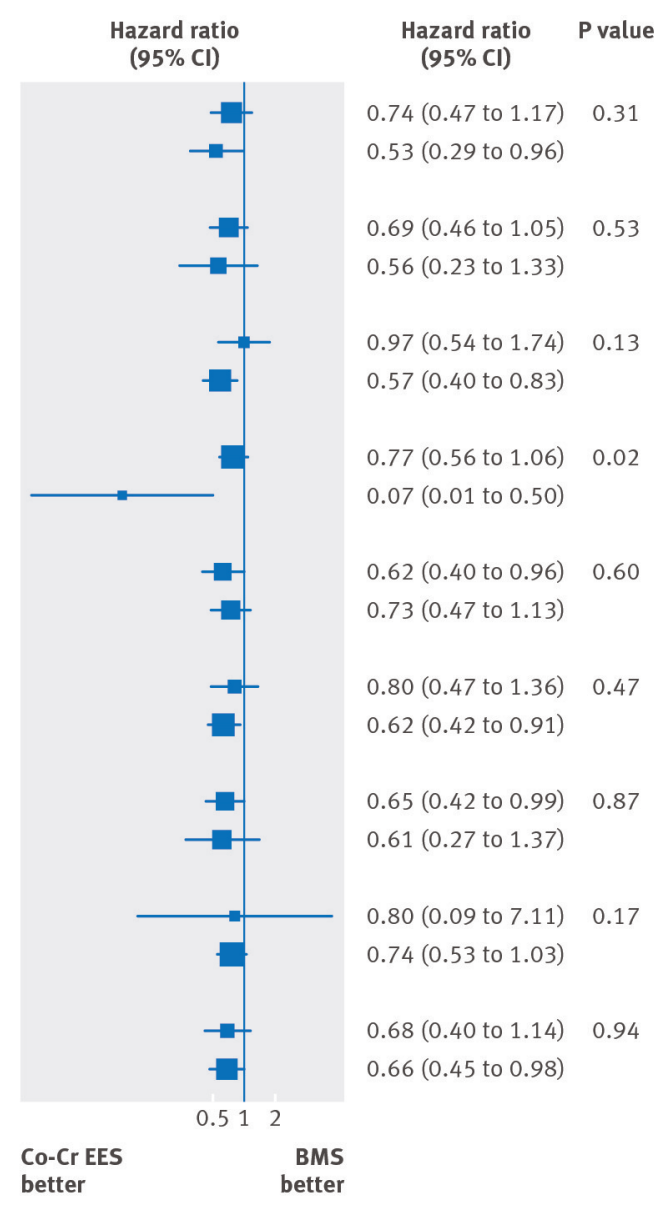

Fig 9 Subgroup analyses for treatment effect, with $\mathrm{P}$ value for interaction. Illb/lla=glycoprotein $\mathrm{Ilb} / \mathrm{llla}$ inhibitors 